Anais da Academia Brasileira de Ciências (2006) 78(3): 423-439

(Annals of the Brazilian Academy of Sciences)

ISSN 0001-3765

www.scielo.br/aabc

\title{
Resonance Raman spectroscopy in one-dimensional carbon materials
}

\author{
MILDRED S. DRESSELHAUS ${ }^{1}$, ADO JORIO ${ }^{2}$ and MARCOS A. PIMENTA ${ }^{2}$ \\ ${ }^{1}$ Massachusetts Institute of Technology, 77 Massachusetts Avenue, Cambridge, MA 02139-4307, USA \\ ${ }^{2}$ Departamento de Física, Universidade Federal de Minas Gerais \\ Avenida Antonio Carlos, 6627, 30123-970 Belo Horizonte, MG, Brasil
}

Manuscript received on April 28, 2006; accepted for publication on May 02, 2006;

contributed by MILDRED S. DRESSELHAUS*

\begin{abstract}
Brazil has played an important role in the development and use of resonance Raman spectroscopy as a powerful characterization tool for materials science. Here we present a short history of Raman scattering research in Brazil, highlighting the important contributions to the field coming from Brazilian researchers in the past. Next we discuss recent and important contributions where Brazil has become a worldwide leader, that is on the physics of quasi-one dimensional carbon nanotubes. We conclude this article by presenting results from a very recent resonance Raman study of exciting new materials, that are strictly one-dimensional carbon chains formed by the heat treatment of very pure double-wall carbon nanotube samples.
\end{abstract}

Key words: resonance Raman spectroscopy, carbon nanotubes, one-dimensional materials, carbon chains.

\section{INTRODUCTION}

This article is devoted to the important contributions given by Brazilians to one research subfield of Condensed Matter Physics, that of Raman spectroscopy. The Brazilians in the past have an impressive historical record for important contributions to Raman Spectroscopy. Their leadership in the field has benefited Brazilian Science overall by giving excellent training to young people and giving them a vision that they can contribute importantly to world science much more broadly. This tradition of leadership continues to the present.

An important contribution Brazilians have recently made is to recognize how Raman scattering could become a useful tool for nanoscience, even though the wavelength of light is much larger than the nanometer scale. In 1998, it was shown that Raman spectroscopy can investigate metallic and semiconducting SWNTs independently. In 2001, it was shown that single nanotube

PACS numbers: 78.30.Na, 78.20.Bh, 78.66.Tr, 63.22.+m, 36.20Kd, 36.20.Ng

* Member Academia Brasileira de Ciências

E-mail: millie@mgm.mit.edu/ adojorio@fisica.ufmg.br/mpimenta@ fisica.ufmg.br 
spectroscopy could be done, and this technique provided new information not previously available, like the structural identification of individual tubes, thereby allowing investigation of many materials properties, not previously accessible. Later, the Brazilians showed how nanostructures can be probed in a new way by making studies with many laser lines. Others may have also had this capability, but they did not develop this approach into a form where interesting three-dimensional maps highlighting important physical effects could be made. With this tunable laser system many findings were made that could not have been observed before, and these findings have had a lot of impact. Researchers worldwide have now started to pay attention to this way of doing Raman characterization of materials.

Nowadays Brazil is the place where they have the experimental know-how and the vision of important physics problems awaiting solution in the area of carbon nanotube photophysics. Here we first revisit the past, giving a few examples of how this structure and scientific atmosphere was built. Next we briefly list some of the recent contributions from Brazilians to nanoscience.

\section{RAMAN SCATTERING RESEARCH IN BRAZIL}

This section gives some examples of Brazilians contributions to world science, and reviews the impacts of a few distinguished leaders in building a rich scientific atmosphere within Brazil. There is no intention to give a full and complete historical survey of Raman spectroscopy in Brazilian science.

The Raman effect was first discovered in India by C.V. Raman in 1928 (Raman 1930). Raman was awarded the Nobel Prize in physics in 1930 for his discovery of the effect which carries his name. Following the discovery of the Raman effect, most of the effort by the scientific community was on measuring the Raman spectra from many different materials and on developing new spectroscopic techniques.

A large contribution to this field was made by Hans Stammreich, who was the one responsible for the introduction of Raman spectroscopy into Brazil. Stammreich was born in 1902, in Germany. He went to Brazil in 1940, becoming a Professor three years later in the Department on Physics at the Universidade de São Paulo (USP). In the following years he developed, with the collaboration of O. Sala, R. Forneris and A.G. Ayrosa, the technique of the excitation of Raman spectra with helium lamps, and it was Stammreich who introduced into Raman instrumentation the use of spectrographs based on diffraction gratings (Stammreich 1956). Stammreich is responsible for the first Raman spectra of an impressive number of materials, and from the 86 publications of Stammreich, 56 were made while he was in Brazil. He is remembered for his special dedication to teaching, and he left behind a legacy of high quality scientists and a large number of Brazilian students, well trained in Raman spectroscopy research, and these students then spread both the scientific spirit and Raman spectroscopy techniques throughout Brazil.

As one of many examples of Stammreich's legacy we can cite the contributions of his student Osvaldo Sala (Ph.D. in 1964 from the University of São Paulo), who later became a professor in the Chemistry Department at the University of São Paulo. Sala was one of the pioneers in the study of the surface enhanced Raman scattering (SERS) effect (Rubim et al. 1983) and he made a large contribution to Raman scattering studies of metals (Stammreich et al. 1958, 1959, 1961a, b). 
The knowledge and use of the Raman effect took a big leap forward in the 1960s, when a Brazilian physicist, Sergio P.S. Porto first used a laser to probe the Raman spectra of different kinds of materials. Sergio Pereira da Silva Porto was born in Niterói, Rio de Janeiro, in 1926. He received his Ph.D. degree in 1954 at the Johns Hopkins University, for work on the study of the spectra of $\mathrm{H}_{2}$ and $\mathrm{H}_{2} \mathrm{O}$ molecules, and is still remembered at Johns Hopkins for trying surreptitiously to adapt their large Littrow spectrograph for Raman Spectroscopy. After his doctorate, he returned to Brazil to take a position as an Assistant Professor of Physics at the Aeronautical Technology Institute (ITA), where he built several spectroscopic instruments, including a high resolution double grating spectrometer. In 1960 he joined Bell Laboratories in the USA to work on the development of laser materials. Soon afterward, he recognized the potential of the laser as a tool for Raman spectroscopy (Leite and Porto 1966). This finding, together with his talent for instrumentation, brought laser spectroscopy into a new era. Sergio's laboratory at Bell Labs soon became one of the most important laboratories in the field of solid state spectroscopy. While at Bell Labs, he observed for the first time Raman scattering from F-centers (Worlock and Porto 1965), polaritons in ionic crystals (Porto et al. 1966), light scattering from spin waves (magnons) (Fleury et al. 1966) and optical activity in Raman spectra (Scott and Porto 1967). In 1967 Sergio Porto accepted a position as Professor of Physics and Electrical Engineering at the University of Southern California (USC). While at USC he continued to make important contributions to Raman scattering, including the observation of anti-symmetric electronic Raman scattering (Kiel et al. 1968), the Raman cross-section of gases (Weber et al. 1967), symmetry-forbidden first-order Raman spectra in disordered solids, (Williams and Porto 1973, Rao et al. 1974) and studies of phase transitions (Rao et al. 1972) and soft modes (DiDomenico et al. 1967). In addition, Porto supervised many Brazilian students who went to USC to have the opportunity to work with him.

In 1973 Porto returned to Brazil, to join the recently founded Physics Institute at the State University at Campinas (Unicamp), where he led a group of researchers to study lasers and their applications. In 1974 he founded the Quantum Electronics Department of the Physics Institute at Unicamp. Porto had a strong commitment to high quality research and education and he was essential in defining the early history of Unicamp as a major university worldwide. Porto was appointed Dean of Research of the University of Campinas in 1976, where he also held several other top management positions. Wherever he was, he always contributed ideas towards building excellence in education and research. Sergio Porto died in 1979 in Novosibirsk, Siberia, while attending an International Laser Physics Conference. Though he died at a relatively early age, he left behind a legacy of high quality work, a contagious excitement for science, and a large number of Brazilian students, well trained in Raman spectroscopy research. These students have subsequently had a large influence on Brazilian science.

Due to the large efforts of many scientists like Porto, Campinas became an important research center for Brazilian and worldwide science. Among several important researchers, we mention R.C.C. Leite, who worked with Porto at Bell Labs in the 1960s. A few examples of the large scientific contributions of Leite are his discovery with Porto of the resonance Raman effect (Leite and Porto 1966, Scott et al. 1969) and his important works on semiconductors physics, such as the study of donor-acceptor pair recombination in n-type GaAs (Leite and DiGiovanni 1967), of 
injection mechanisms in GaAs diffuse electroluminescent junctions (Leite et al. 1965), of longtransient effects in lasers with lasers with inserted liquid samples (Gordon et al. 1965) and of light propagation in p-n junctions through a dielectric-wave guide mode (Yariv and Leite 1963). Leite returned to Brazil in 1971 to become a Full Professor at Unicamp and had a large impact on the Department at Unicamp by attracting many talented scientists and by bringing many financial resources to Unicamp. Together with Porto and Minko Balkanski, Leite also edited the book "Light Scattering in Solids" (Balkanski et al. 1976) which was the proceedings of a large and important international conference on light scattering held in Brazil in 1975.

Not only did Porto make contributions to Raman spectroscopy worldwide, but we can also link to him many other researchers who made important contributions to Brazilian science. Two examples of other Brazilian universities where researchers had the chance to have close contact with Porto are in the Physics Departments at Universidade Federal de Minas Gerais (UFMG) and Universidade Federal do Ceará (UFC).

A.S. Chaves and G.A. Barbosa received their PhD degrees with Porto at the University of Southern California, in the 1970s. Barbosa studied the temperature dependence of the Raman cross-section in $\mathrm{BaTiO}_{3}$ and $\mathrm{SrTi}_{3}$ (Barbosa et al. 1972). Chaves worked on phonon-polaritons in ferroelectric systems. Among his important contributions to the field of Raman spectroscopy we can cite the observation of dynamic disorder in crystals using Raman scattering (Chaves et al. 1974) and a generalization of the Lyddane-Sachs-Teller relation for ordered-disordered crystals (Balkanski et al. 1976). Chaves and Barbosa returned to Brazil and later became full Professors at the Universidade Federal de Minas Gerais (UFMG), and both have had a large impact on local and national scientific development in Brazil.

Barbosa installed the first experimental laboratory in quantum optics in Brazil and made important contributions to this field (Ribeiro et al. 1994a, b). His PhD student, P.H.S. Ribeiro was awarded the Prize for the best PhD Brazilian thesis in Physics in 1997, for the work "Study of the Properties of Light Coherence Produced in Parametric Down-conversion" (Ribeiro 1995). In 1998 Ribeiro went to the Universidade Federal do Rio de Janeiro and installed the first experimental laboratory for quantum optics in the state of Rio de Janeiro.

Chaves led the creation of the Semiconducting Physics Group at UFMG and he is the author of Physics books for undergraduates studying physical sciences and engineering (Chaves 2002). In the hands of Ramayana Gazzinelli, with the help of Chaves, Barbosa and others, the Physics Department at UFMG created a scientific atmosphere with a strong focus on the development on experimental physics. The Raman laboratory in the Physics Department at UFMG, which was installed in 1992 by M.A. Pimenta, has had a worldwide influence on the resonance Raman scattering research of graphite and carbon nanotubes, as discussed in this review.

J. Mendes Filho and F.E.A. Melo received their Ph.D. degrees at Unicamp, in the 1980s, Mendes Filho being the last student of Porto, although Porto died before signing his Thesis. Mendes Filho worked on the use of Raman scattering to study phase transitions in $\beta$ - $\mathrm{LiTiO}_{3}$, (Mendes Filho 1984) while Melo worked on lattice dynamics and anharmonic effects in ionic crystals (Melo 1983). They both became Full Professors of Physics at the Universidade Federal do Ceará (UFC) and also had a large impact on local and national scientific developments. Mendes Filho led the Physics 
Department in UFC for many years and installed different laboratories for experimental physics, including a Raman laboratory which had a high level of activity in studying phase transitions and pressure-induced effects. He was also the first researcher to perform polarized Raman experiments inside a pressure cell (Mendes Filho et al. 1984). The Raman lab also made important contributions to studying Raman phenomena in different kinds of materials, such as ceramics and ferro-electrics, and more recently nanostructured materials, including carbon nanotubes. His PhD student, A.G. Souza Filho was awarded an "Honorable Mention" for his PhD thesis work in 2002, from the Brazilian Physical Society. His work was on electronic, structural and vibrational properties of carbon nanotubes and $\mathrm{PbZr}_{1-x} \mathrm{Ti}_{x} \mathrm{O}_{3}$ ferroelectric systems (Souza Filho 2001).

After revisiting the past, showing how important was the Brazilian contribution to Raman spectroscopy, we next discuss recent examples showing that Brazilians are also playing a very important role at present in the development of materials science, more specifically the nanoscience of carbon materials, based on resonance Raman spectroscopy, which has a long history in Brazil. Here we discuss the use of resonance Raman spectroscopy to characterize the electronic and vibrational properties of quasi-one dimensional carbon nanotubes, and next to study the strictly onedimensional carbon chains, which is a newly emerging topic in carbon based physical-chemistry.

\section{THE RESONANCE RAMAN SPECTROSCOPY OF ONE-DIMENSIONAL CARBON MATERIALS}

Raman scattering involves the inelastic scattering of light by any kind of excitation in a material. By excitations, we mean electronic excited states, phonons (quanta of lattice vibration), plasmons (quanta of plasma oscillations), magnons (quanta of spin waves), excitons (bound electron-hole pairs), and it is these same excitations that are usually responsible for the thermal, optical, magnetic and transport properties of matter. Light is pumped onto the material under study, and the scattered radiation carries information about the interaction of photons with each type of excitation in the material. Carbon materials have been central to the Raman scattering technique. In fact, C.V. Raman discovered the Raman effect in 1928 while studying carbon materials (Raman 1930). Nowadays Raman spectroscopy is one of the most important techniques used for the study and characterization of recently discovered carbon materials, such as carbon nanotubes (Dresselhaus et al. 2002, Jorio et al. 2004, 2003a). The topic of Raman spectroscopy in carbon materials is particularly appropriate for this review article because of the close connection between Raman scattering and Brazilian science both from a historical perspective (see previous section) and from the viewpoint of current research developments.

The use of the resonance effect in Raman spectroscopy substantially increases the power of the technique. The intensity of the Raman peak is enhanced when the incident or the scattered photon is in resonance with an electronic transition in the material. By studying the intensity of the Raman peak as a function of the excitation laser energy $\left(E_{\text {laser }}\right)$, one can obtain information about the electronic structure. In addition, variation of $E_{\text {laser }}$ provides new power to the Raman technique, special for the study of one-dimensional carbon materials. The importance of this technique to actual science was realized by the authors of the review, as we discuss below. 
Resonance Raman Spectroscopy of Quasi-One Dimensional Carbon Nanotubes

Single wall carbon nanotubes (SWNTs) have been the focus of intensive work for fundamental studies, and are a potential nano-material for applications involving interdisciplinary fields, joining physics, chemistry, engineering, and biology (Saito et al. 1998). Different kinds of SWNTs, as determined by their tubular structures, i.e., diameter $\left(d_{t}\right)$ and chirality $(\theta)$, exhibit different properties (Saito et al. 1998). The SWNT is a single sheet of graphite (graphene) rolled up into a seamless cylinder of $\sim 1 \mathrm{~nm}$ in diameter. The structure of a given SWNT can be defined by the chiral vector $C_{h}$, which spans the circumference of the tube, and the vector $C_{h}$ can be denoted by a pair of indices $(n, m)$, which describes $C_{h}$ as a function of the graphene lattice unit vectors $\left(C_{h}=n a_{1}+m a_{2}\right)$. The physical properties of carbon nanotubes depend strongly on $(n, m)$. Special attention can be given to the fact that SWNTs can be metallic if $(n-m)$ is a multiple of 3 , or semiconducting otherwise (Saito et al. 1998). The characterization of nanotube structures, given by their indices $(n, m)$ is, therefore, of major importance for the development of carbon nanotube science and applications. The unique optical and spectroscopic properties observed in single wall carbon nanotubes are largely due to the one-dimensional (1D) confinement of electronic and phonon states and due to the resonance Raman processes. Because of this $1 \mathrm{D}$ confinement, the resonance effect is both strongly enhanced relative to graphite and highly selective of the SWNT geometric $(n, m)$ structure. Thus Raman spectroscopy has become not only a spectroscopic tool, but also has become a structural characterization tool for SWNTs.

The power of Raman spectroscopy for the characterization of carbon nanotubes was first demonstrated, in 1997, by Rao et al. who showed a dependence of the Raman spectra from SWNT bundles on the excitation laser energy $E_{\text {laser }}$, due to a strong resonance effect between $E_{\text {laser }}$ and the sharp van Hove singularities in the joint density of electronic states in one-dimensional SWNTs. In 1998 it was shown by M. A. Pimenta from UFMG while visiting MIT that the resonance Raman effect could be used to distinguish between metallic (M) and semiconducting (S) SWNTs (Pimenta et al. 1998) and how to probe $\mathrm{M}$ and $\mathrm{S}$ semiconducting separately.

The distinction between M and S SWNTs utilizes the different line shapes of the tangential mode vibrations, as shown in Fig. 1(a). This Raman feature is called the $G$ band, $G$ denoting graphite-like. In graphite the feature has a single peak, since in-plane tangential vibrations are degenerate in the hexagonal sheet. In nanotubes this feature splits into up to 6 peaks due to the curvature of the graphene sheet and the quantum confinement along the tube circumference (Jorio et al. 2000, 2002a, b, 2003b).

This difference in line shape between M and S SWNTs is best observed in SWNT bundle samples since the coupling of the conduction electrons to phonons through a plasmon excitation is enhanced by intertube interactions (Kataura et al. 1999, Brown et al. 2001). By measuring the Raman spectra of nanotube bundles through varying $E_{\text {laser }}$, as shown in Fig. 1(a), different tubes

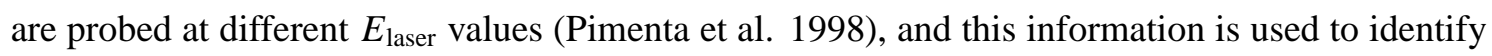
$\mathrm{M}$ and S SWNTs in Fig. 1(b). Based on the line shape fits of the $G$ feature for S and M SWNTs, the various traces in Fig. 1(a) are identified in Fig. 1(b) with the resonance of the excitation laser with specific semiconducting and metallic SWNTs contained within the sample. 
(a)

(b)

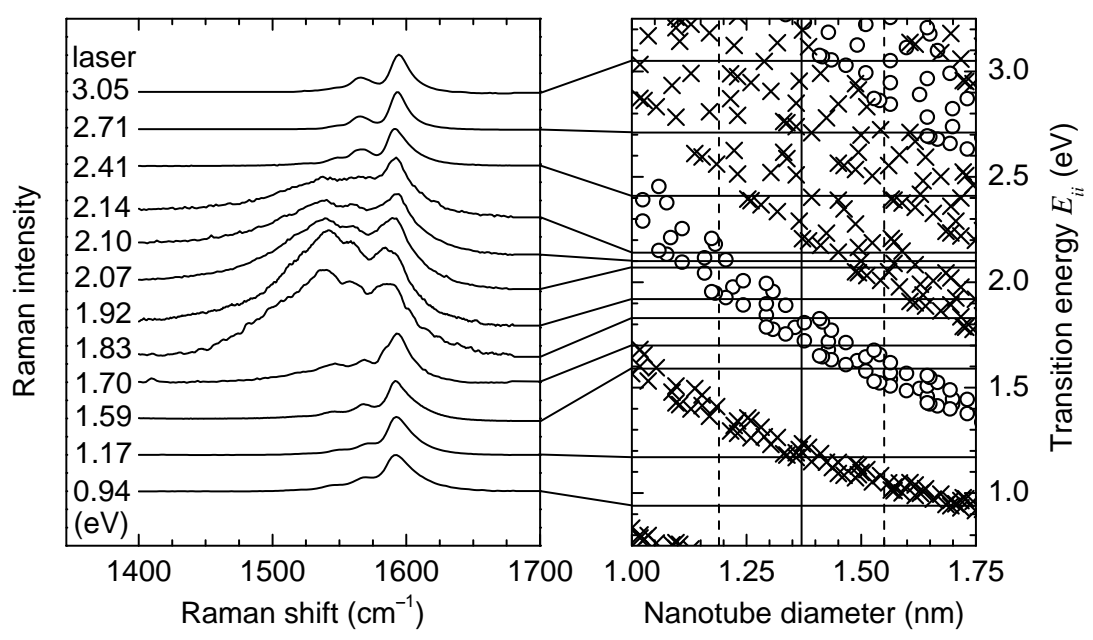

Fig. 1 - (a) Raman spectra of the tangential $G$-band modes of SWNT bundles measured with several different laser lines, on a sample with $d_{t}=1.37 \pm 0.18 \mathrm{~nm}$ (Pimenta et al. 1998). (b) Resonant transition energies $E_{i i} v s$. $d_{t}$. The vertical solid line is the average $d_{t}$ and the vertical dashed lines denote the $d_{t}$ distribution width. Crosses are for S SWNTs and open circles for M SWNTs (Samsonidze et al. 2003).

The next important step forward in the spectroscopic studies of carbon nanotubes occurred in 2001, when A. Jorio from UFMG, while visiting MIT, showed that it was possible to measure the Raman signal from one isolated single-wall carbon nanotube (Jorio et al. 2001a) (see Fig. 2), and that the Raman spectroscopy could be used to determine the SWNT geometric structure by a direct evaluation of the $(n, m)$ indices for individual SWNTs (Jorio et al. 2001a). For the spectroscopic assignment of the two SWNT indices $(n, m)$, experimental determination of two nanotube properties is necessary: the electronic transition $E_{i i}(i=1,2,3 \ldots$, giving the number of the electronic transition energy relative to the Fermi level of the unperturbed SWNT) and the nanotube radial breathing mode frequency $\left(\omega_{\mathrm{RBM}}\right)$. Therefore, once one measures a set of these two SWNT properties, a structural assignment can be made by using a model which directly relates the $\left(E_{i i}, \omega_{\mathrm{RBM}}\right)$ to $(n, m)$. The relation $\omega_{\mathrm{RBM}}=248 / d_{t}$ was obtained by A. Jorio, and this important result has been included in the $8^{\text {th }}$ edition of the popular textbook "Introduction to Solid State Physics", by C. Kittel (Kittel 2005). This work and much of the science about single nanotube spectroscopy was subsequently developed through a strong and fruitful collaboration between the Physics Departments at the Universidade Federal de Minas Gerais (UFMG), Brazil (CNPqNSF), and those at the Massachusetts Institute of Technology (MIT), USA, and at the Tohoku University (TU), Japan.

From this initial work, the importance of the resonance Raman scattering (RRS) technique to study and characterize the one-dimensional structure of carbon nanotubes became clear. In 2002 the Physics Department at UFMG established the Brazilian Nanoscience Institute (Millennium Program - MCT and CNPq), and its Raman laboratory put its efforts into building a quasi-continuous 

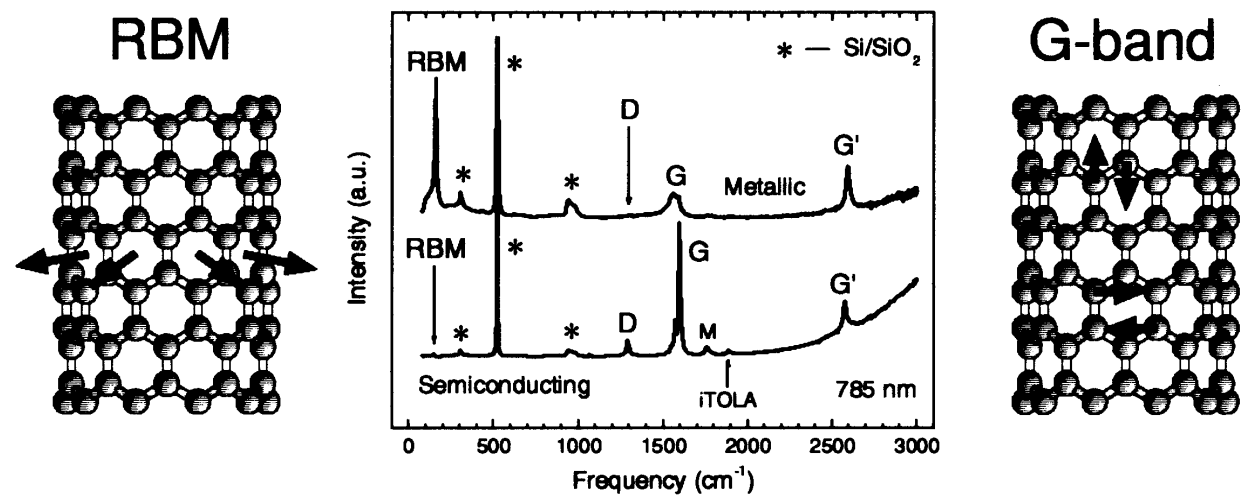

Fig. 2 - Raman spectra from a metallic (top) and a semiconducting (bottom) SWNT at the single nanotube level using $785 \mathrm{~nm}(1.58 \mathrm{eV})$ laser excitation, showing the radial breathing mode (RBM), $D$-band, $G$-band, and $G^{\prime}$ band features, in addition to weak double resonance features associated with the M-band and the iTOLA second-order modes. Insets on the left and the right show, respectively, the atomic displacements associated with the RBM and $G$-band normal mode vibrations. The isolated carbon nanotubes are sitting on an oxidized silicon substrate which provides contributions to the Raman spectra denoted by '*' which are used for calibration purposes.

laser excitation system to be able to study the effect of one-dimensional van Hove singularities. Experiments carried out at UFMG showed that by using a tunable system to tune over one electronic transition $E_{i i}$ for a single isolated nanotube, it is possible to determine $E_{i i}$ and the resonance width $\Gamma$ (see Fig. 3). Such an experiment was performed for a SWNT with $\omega_{\mathrm{RBM}}=173.6 \mathrm{~cm}^{-1}$, i.e., $d_{t}=248 / 173.6=1.43 \mathrm{~nm}$ (Jorio et al. 2001b). Very accurate values for $E_{i i}=1.655 \pm 0.003 \mathrm{eV}$ and $\Gamma=8 \mathrm{meV}$ were found from Fig. 3. Knowing $d_{t}$ and $E_{i i}$ allowed the assignment of the measured SWNT as the $(18,0)$ metallic SWNT (Jorio et al. 2001b). By doing the experiment with a tunable laser, one can measure the resonance line shape profile experimentally. At the upper inset of Fig. 3, it is shown that the resonance window for the Stokes (creating of a phonon) and anti-Stokes (annihilation of a phonon) spectra are displaced from each other. This effect occurs because the enhancement depends on the energy of both the incident and scattered photons, and the scattered photons differ in energy by $\pm \hbar \omega_{\mathrm{ph}}$, where $\omega_{\mathrm{ph}}$ is the phonon frequency.

In 2004, resonance Raman spectroscopy was used to determine the optical transition energies for different $(n, m)$ single-wall carbon nanotubes in solution (Fantini et al. 2004). Figure 4 presents Stokes resonance Raman measurements of carbon nanotubes grown by the HiPco process, dispersed in aqueous solution and wrapped with sodium dodecyl sulfate (SDS) (O'Connell et al. 2002), in the frequency region of the RBM features. A total of 76 excitation laser lines were used to construct this map. The quasi-continuous variation of $E_{\text {laser }}$ from $1.52 \mathrm{eV}$ up to $2.71 \mathrm{eV}$ provides us with detailed information about the evolution of the RBM Raman spectra as a function of $E_{\text {laser. }}$. Many RBM peaks appear in Fig. 4, each peak corresponding to a carbon nanotube in resonance with $E_{\text {laser }}$, thereby delineating for each nanotube the resonance window (Raman intensity as a function of the energy in the range where the RBM feature can be observed). The frequency 


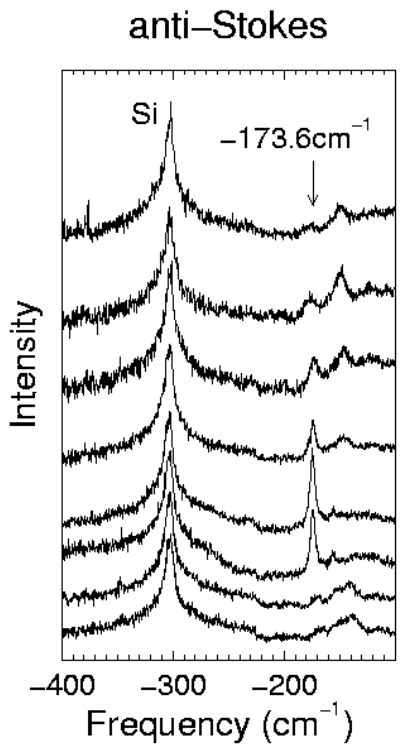

(a)

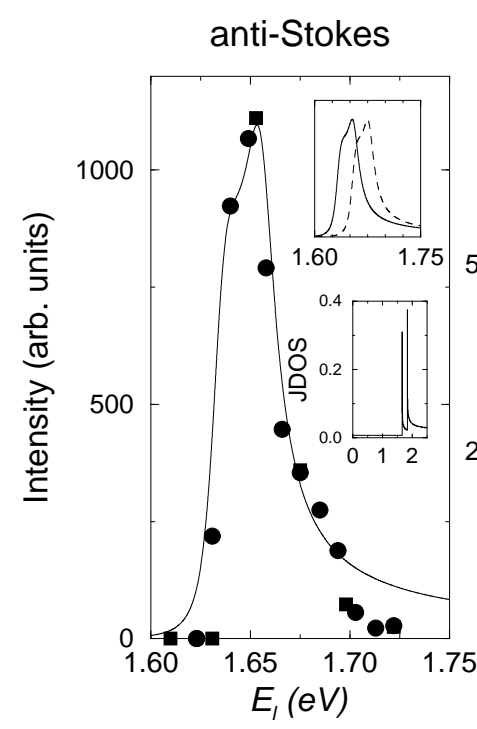

(b)

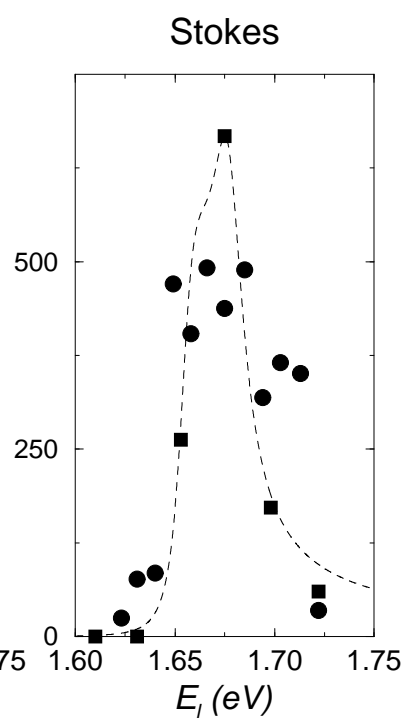

(c)

Fig 3 - (a) The $E_{\text {laser }}$ dependence of the anti-Stokes Raman spectra from a SWNT grown on a $\mathrm{Si} / \mathrm{SiO}_{2}$ substrate using the CVD method. The spectra from bottom to top were taken by varying $E_{\text {laser }}$ from $1.623 \mathrm{eV}$ up to $1.772 \mathrm{eV}$. The peak at $-303 \mathrm{~cm}^{-1}$ comes from the substrate and it was used for calibration of the Raman signal. The peak at $-173.6 \mathrm{~cm}-1$ is related to the RBM from a SWNT. This feature appears and disappears as the laser is tuned to achieve resonance. (b) Resonance profile (RBM intensity vs. $E_{\text {laser }}$ ) for the anti-Stokes RBM spectra shown in (a). (c) Resonance profile for the Stokes spectra (not shown). The Stokes signal is noisier because the scattered light energy falls in the range where the spectrometer gratings are losing efficiency. The solid and dashed lines in (b) and (c) are fit to experimental points (see text). The upper inset to (b) shows the Stokes and anti-Stokes fitting curves together. The lower inset to (b) shows the sharp JDOS used to reproduce the fit in (b) and (c) (Jorio et al. 2001b).

$\omega_{\mathrm{RBM}}$ is directly determined from the Raman spectra with $0.5 \mathrm{~cm}^{-1}$ accuracy. The electronic transition energy determination $E_{i i}$ is obtained with $\pm 10 \mathrm{meV}$ accuracy by analyzing the Stokes and anti-Stokes resonance windows for each RBM peak. Here we obtained $\left(E_{i i}, \omega_{\mathrm{RBM}}\right)$ for 46 different $(n, m)$ SWNTs, including 28 semiconducting and 18 metallic SWNTs. These studies allowed the development of more reliable models to describe the detailed electronic structure of SWNTs, including effects due to SWNT curvature and related to $(2 n+m)$ family behavior, as well as many-body effects (Samsonidze et al. 2004, Jorio et al. 2005). Furthermore, through these measurements, the important equivalence was demonstrated between the optical transition energies $E_{i i}$ obtained by resonance Raman spectroscopy and photoluminescence excitation (PLE) spectroscopy (O'Connell et al. 2002).

\section{Resonance Raman Spectroscopy of Strictly One-Dimensional CaRbon Chains}

Strictly speaking, a one-dimensional carbon material is a chain of single carbon atoms. Prior Raman studies of long linear chains of $s p$-bonded carbon atoms, also known as carbynes, (Kurti 


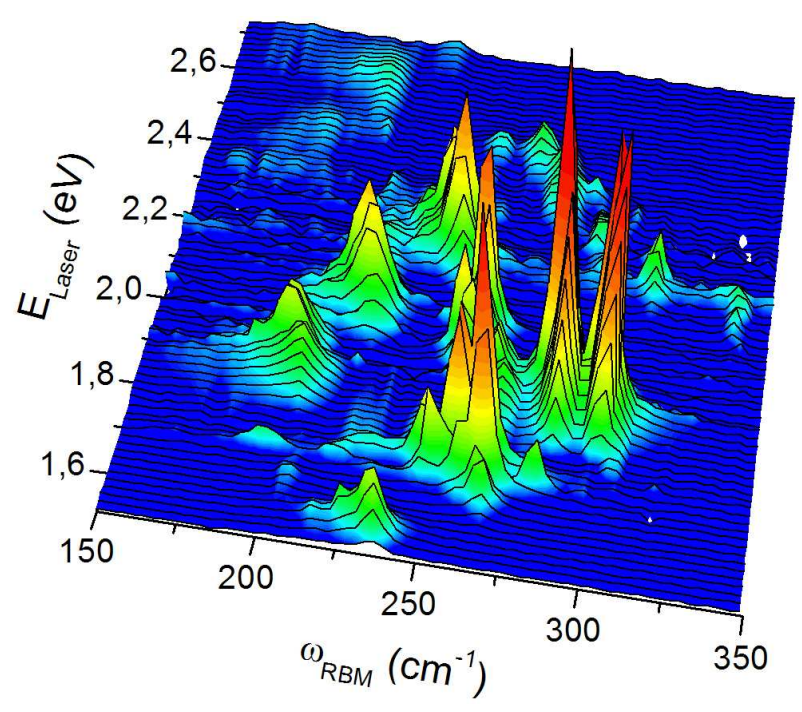

Fig. 4 - RBM Raman measurements of HiPco SWNTs dispersed in SDS aqueous solution, measured with 76 different laser lines (Fantini et al. 2004). The nonresonance Raman spectrum from a separated $\mathrm{CCl}_{4}$ solution is acquired after each RBM measurement, and is used to calibrate the spectral intensities and to check the frequency calibration. Each Raman peak comes from the radial breathing mode (RBM) of a specific $(n, m)$ single-wall carbon nanotube that enters and leaves resonance. The RBM frequencies are inversely proportional to the nanotube diameters.

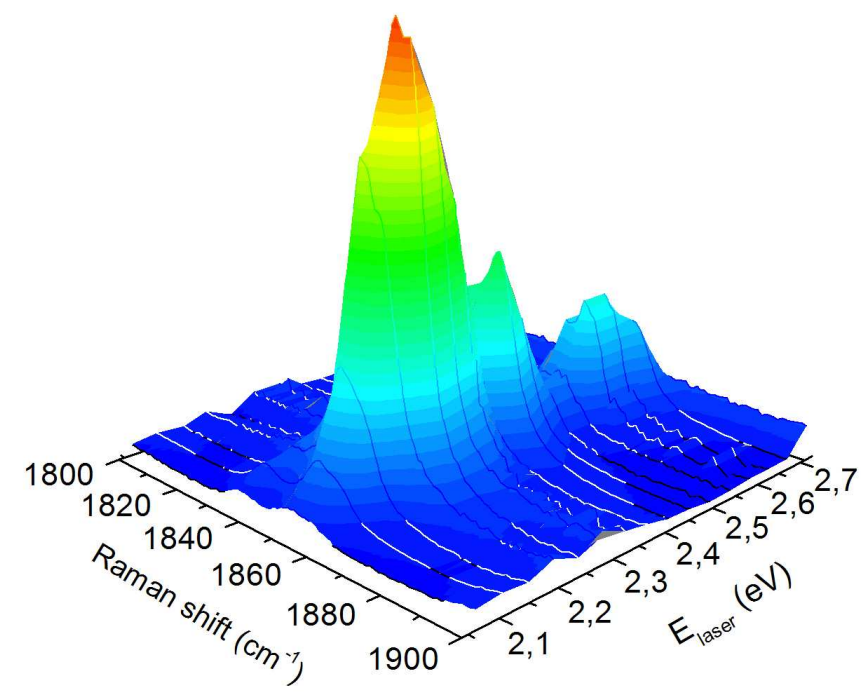

Fig. 5-3D plot for the resonance Raman profile of the $1850 \mathrm{~cm}^{-1}$ carbon chain Raman peak (Fantini et al. 2006). The chains are formed by heat treatment at $1500^{\circ} \mathrm{C}$ of undoped DWNTs. A strong resonance at $E_{\text {laser }}=2.2 \mathrm{eV}$ is observed.

et al. 1995) show a broad Raman peak at $2000 \mathrm{~cm}^{-1}$. The observation of unusual and strong spectral features around $1850 \mathrm{~cm}^{-1}$ has been reported recently in the Raman spectra of carbon nanotube systems, (Zhao et al. 2003, Jinno et al. 2006, Endo et al. 2006) and these features 
have been ascribed to the vibration of strictly one-dimensional (1D) chains of carbon atoms. In particular, a strong and sharp feature at $\sim 1850 \mathrm{~cm}^{-1}$ was observed in the Raman spectra of double wall nanotube (DWNT) samples heat treated at high temperatures (Endo et al. 2006) and, since this Raman feature only appears at specific annealing temperatures $\left(T_{\mathrm{htt}}\right)$ that occur just below the $T_{\mathrm{htt}}$ needed for full coalescence of DWNTs, it was named the coalescence-inducing mode (CIM). To characterize this unusual Raman feature at $\sim 1850 \mathrm{~cm}^{-1}$, we performed a detailed resonance Raman study of this phonon band, using many different laser excitation energies $\left(E_{\text {laser }}\right)$ (Fantini et al. 2006).

Room temperature Raman spectra were recorded in the backscattering configuration using the Dilor XY triple monochromator, using several different laser line excitations from an $\mathrm{Ar}-\mathrm{Kr}$ ion laser, and a dye laser in the range 1.9-2.7 eV. A laser power of $<1 \mathrm{~mW}$ was focused on a $\sim 2 \mu \mathrm{m}^{2}$ spot during the measurements. The samples studied consist of highly purified DWNT bundles synthesized by a catalytic chemical vapor deposition method (Endo et al. 2005a, b). The diameter distribution of the samples is $0.77 \leq d_{t} \leq 0.90 \mathrm{~nm}$ for the inner tubes and $1.43 \leq d_{t} \leq 1.60 \mathrm{~nm}$ for the outer tubes (Endo et al. 2005a, b). Both undoped and B-doped DWNTs were investigated, after heat treatment at $T_{\mathrm{htt}}$ between 1000 and $2000^{\circ} \mathrm{C}$. The addition of boron was shown to facilitate the formation of the carbon chains at lower heat treatment temperatures. The CIM feature reaches its maximum intensity for the undoped sample when $T_{\mathrm{htt}}=1500^{\circ} \mathrm{C}$, and for the B-doped DWNTs when $T_{\mathrm{htt}}=1300^{\circ} \mathrm{C}$ (Endo et al. 2006).

The resonance behavior of the $1850 \mathrm{~cm}^{-1}$ (CIM) Raman feature observed in heat treated DWNT bundle samples was studied. Figure 5 shows a 3D plot of Raman shift vs $E_{\text {laser }}$ vs Raman intensity for resonant Raman measurements on the undoped sample after heat treatment at $1500^{\circ} \mathrm{C}$, and the resonance behavior in the intensity of the CIM feature is clearly observed. It was observed that the intensity of the CIM band depends strongly on the laser energy and exhibits a maximum value at $E_{\text {laser }}=2.2 \mathrm{eV}$, as shown in Fig. 5 .

Figure 6(a) shows a detailed analysis of the CIM Raman spectra obtained with $E_{\text {laser }}=2.20 \mathrm{eV}$ (where the CIM feature shows its maximum intensity), from four different sample locations of the laser spot on the undoped specimen $\left(T_{\mathrm{htt}}=1500^{\circ} \mathrm{C}\right)$ (Fantini et al. 2006). We observed that the detailed line shape and the mean frequency of the CIM band is somewhat dependent on the position of the laser spot on the sample. The CIM features obtained in all measured spectra were fitted by a sum of Lorentzian peaks, each one with a linewidth of $\sim 10 \mathrm{~cm}^{-1}$, also in agreement with the linewidth of the peaks previously observed in MWNT samples (Zhao et al. 2003). The CIM feature in annealed DWNTs is clearly composed of more than one peak, and up to four peaks were necessary to fit all observed spectra (see Fig. 6(a)). Four frequencies at $\sim 1837 \mathrm{~cm}^{-1}, \sim 1844 \mathrm{~cm}^{-1}$, $\sim 1851 \mathrm{~cm}^{-1}, \sim 1857 \mathrm{~cm}^{-1}$, with a precision of $\pm 2 \mathrm{~cm}^{-1}$ could be clearly distinguished. The two highest frequency peaks are the most intense ones, and the peaks $\sim 1844 \mathrm{~cm}^{-1}$ and $\sim 1837 \mathrm{~cm}^{-1}$ are less intense and sometimes absent in the spectra. The frequency values obtained from the analysis of all spectra, recorded with different laser excitation energies, are shown in Fig. 6(b) as a function of $E_{\text {laser. }}$. The absence of a dispersive behavior demonstrates that these peaks are not related to the combination modes present in all graphitic materials (Brar et al. 2002), and reveals that the CIM band is a first-order Raman scattering process associated with the novel form of 


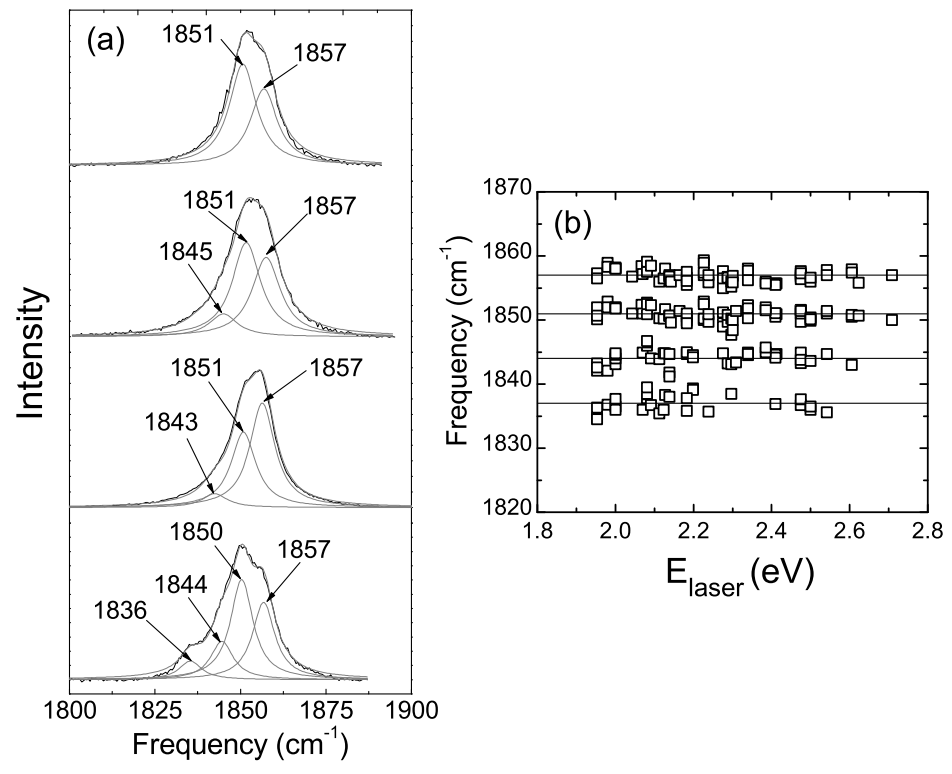

Fig. 6 - (a) First order CIM bands obtained for $E_{\text {laser }}=2.2 \mathrm{eV}$ at different locations on an undoped sample heat treated at $1500^{\circ} \mathrm{C}$. The spectra are fit with a sum of Lorentzians and their frequencies are displayed in $\mathrm{cm}^{-1}$. (b) Frequency vs. $E_{\text {laser }}$ for all Lorentzian peaks used to fit the CIM feature (Fantini et al. 2006).

one-dimensional carbon chains.

One explanation for the observation of up to four peaks in the CIM feature could be chains with different number of carbon atoms. In this case, however, their gap would also depend on the number of carbon atoms, and we should observe a rough dispersive behavior when changing $E_{\text {laser }}$. Since this is not observed, we rule out this possibility. It is known that an infinite linear chain with one atom per unit cell ( $=C=C=C=$ ) does not have a Raman active mode. Molecular dynamics calculations show that carbon chains containing 3, 4 and 5 atoms covalently linking the inner and the outer tubes can be formed (Fantini et al. 2006). The existence of a stable linear chain with more than 8 atoms seems unlikely for DWNTs during coalescence. Calculated results for the vibrational normal mode frequencies and energy gaps of linear chains with a small number of carbon atoms, with fixed and free ends have also been performed (Fantini et al. 2006). Qualitative agreement with experimental results is obtained for $\mathrm{C} 5$ and $\mathrm{C} 7$ chains with fixed ends. Furthermore, small twists and bending of these small chains can change their vibrational frequencies by values up to $100-150 \mathrm{~cm}^{-1}$ (Fantini et al. 2006). Based on these arguments, we propose that the CIM feature should be related to linear carbon chains with a small and odd number of carbon atoms.

\section{FINAL REMARKS}

In this article we show highlights of contemporary advances in resonance Raman spectroscopy where Brazilian scientists are playing a dominant role. Some historical perspectives are given 
showing the important role that Brazilian science played historically in the development of Raman spectroscopy and the important role that Raman spectroscopy research has played in the development of experimental physics in Brazil.

\section{ACKNOWLEDGMENTS}

The authors are very thankful for the important contribution of many researchers to this review, including R. Saito, A.G. Souza Filho, C. Fantini, Ge.G. Samsonidze, M. Terrones, M. Strano and M. Endo. M.S.D. acknowledges support under National Science Foundation (NSF) Grants DMR 04-05538. Brazilian authors acknowledges financial support from Instituto de Nanosciências Conselho Nacional de Desenvolvimento Científico e Tecnológico (CNPq).

\section{RESUMO}

O Brasil desempenhou um papel importante no desenvolvimento e no uso da espectroscopia Raman como uma ferramenta poderosa na ciência dos materiais. Apresentaremos aqui uma breve história da pesquisa sobre espalhamento Raman no Brasil, enfatizando as contribuições importantes neste campo realizadas por pesquisadores brasileiros no passado. Em seguida, discutiremos contribuições recentes e importantes onde o Brasil se tornou um líder mundial, ou seja na física dos sistemas unidimensionais chamados nanotubos de carbono. Concluímos este artigo apresentando resultados de um estudo muito recente de um novo material que são cadeias de carbono estritamente unidimensionais formadas pelo tratamento térmico de amostras muito puras de nanotubos de carbono de duas camadas.

Palavras-chave: Espectroscopia Raman, nanotubos de carbono, materiais unidimensionais, cadeias de carbono.

\section{REFERENCES}

BAlKanski M, Leite RCC And Porto SPS. 1976. In: Light Scattering in Solids. Flammarion, Paris, France.

Barbosa GA, Chaves A And Porto SPS. 1972. Temperature dependence of the Raman cross sections in $\mathrm{BaTiO}_{3}$ and $\mathrm{SrTiO}_{3}$. Solid State Commun 11: 1053-1055.

Brar VW, Samsonidze Ge G, Dresselhaus G, Dresselhaus R, Saito AK, Swan Ms, Unlu MS, Goldberg BB, Souza Filho AG ANd Jorio A. 2002. Second-order harmonic and combination modes in graphite, single-wall carbon nanotube bundles, and isolated single-wall carbon nanotubes. Phys Rev B 66: 155418.

Brown SDM, Jorio A, Corio P, Dresselhaus MS, Dresselhaus G, Saito R and Kneipp K. 2001. Origin of the Breit-Wigner-Fano line shape of the tangential $G$-band feature of metallic carbon nanotubes. Phys Rev B 63: 155414.

Chaves A, Katiyar RS And Porto SPS. 1974. Coupled modes with $A_{1}$ symmetry in tetragonal $\mathrm{BaTiO}_{3}$. Phys Rev B 10: 3522-3533.

Chaves AC. 2002. In: Reichman And AfFonso (Eds). Física, volumes 1-4. 
DiDomenico JR M, Porto SPS And Wemple SH. 1967. Evidence from Raman scattering for an overdamped soft optic mode in $\mathrm{BaTiO}_{3}$. Phys Rev Lett 19: 855-857.

Dresselhaus MS, Dresselhaus G, Jorio A, Souza Filho AG And Saito R. 2002. Raman spectroscopy on isolated single wall carbon nanotubes. Carbon 40: 2043-2061.

Endo M, Muramatsu H, Hayashi T, Kim YA, Terrones M and Dresselhaus MS. 2005a. Nanotechnology: 'Buckypaper' from coaxial nanotubes. Nature 433: 476.

Endo M, Muramatsu H, Hayashi T, Kim Ya, van Lier G, Charlier JC, Terrones H, TerRONES M AND DRESSElHAUS MS. 2005b. Atomic nanotube welders: boron interstitials triggering connections in double-walled carbon nanotubes. Nano Lett 5: 1099-1105.

Endo M, Kim Ya, Hayashi T, Muramatsu H, Terrones M, Saito R, Villalpando-Paez F, CHOU SG AND DRESSElHaus MS. 2006. Small 2: (in press).

Fantini C, Jorio A, Souza M, Strano MS, Dresselhaus MS and Pimenta MA. 2004. Optical transition energies for carbon nanotubes from resonant Raman spectroscopy: environment and temperature effects. Phys Rev Lett 93: 147406.

Fantini C, Cruz E, Jorio A, Terrones M, Terrones H, Van Lier G, Charlier J-C, Dresselhaus MS, Saito R, Kim YA, Hayashi T, Muramatsu H, Endo M and Pimenta MA. 2006. Resonance Raman Study of Linear Carbon Chains Formed by the Heat Treatment of Double-Wall Carbon Nanotubes. Phys Rev B 73: 193408-1-4.

Fleury PA, Porto SPS, Cheesman LE and Guggenheim HJ. 1966. Light scattering by spin waves in $\mathrm{FeF}_{2}$. Phys Rev Lett 17: 84-87.

Gordon JP, LeITE RCC, MOORE RS, Porto SPS AND WhInNERy JR. 1965. Long-transient effects in lasers with inserted liquid samples. J Appl Phys 36: 3-8.

Jinno M, ANDo Y, BANDOW S, FAn J, YUdASAKA M AND IIJIMA S. 2006. Raman scattering study for heat-treated carbon nanotubes: The origin of $\approx 1855 \mathrm{~cm}^{-1}$ Raman band. Chem Phys Lett 418 : $109-114$.

Jorio A, Dresselhaus G, Dresselhaus MS, Souza M, Dantas MSs, Pimenta Ma, Rao AM, SAito R, LiU C AND Cheng HM. 2000. Polarized Raman study of single-wall semiconducting carbon nanotubes. Phys Rev Lett 85: 2617-2620.

Jorio A, Saito R, Hafner JH, Lieber CM, Hunter M, McClure T, Dresselhaus G and DRESSElHaus MS. 2001a. Structural $(\mathrm{n}, \mathrm{m})$ determination of isolated single wall carbon nanotubes by resonant Raman scattering. Phys Rev Lett 86: 1118-1121.

Jorio A, Souza Filho AG, Dresselhaus G, Dresselhaus MS, Saito R, Hafner JH, Lieber CM, Matinaga FM, Dantas MSS and Pimenta MA. 2001b. Joint density of electronic states for one isolated single wall carbon nanotube studied by resonant Raman scattering. Phys Rev B 63: 245416.

Jorio A, Souza Filho AG, Dresselhaus G, Dresselhaus Ms, Swan AK, Unlu MS, GoldBerg B, Pimenta MA, Hafner JH, Lieber CM and SAito R. 2002a. G-band resonant Raman study of 62 isolated single-wall carbon nanotubes. Phys Rev B 65: 155412.

Jorio A, Souza Filho AG, Brar VW, Swan AK, Unlu MS, Goldberg BB, Righi A, Hafner JH, Lieber CM, Saito R, Dresselhaus G and Dresselhaus MS. 2002b. Polarized resonant 
Raman study of isolated single-wall carbon nanotubes: Symmetry selection rules, dipolar and multipolar antenna effects. Phys Rev B 65: R121402.

Jorio A, Pimenta MA, Souza Filho AG, Saito R, Dresselhaus G and Dresselhaus MS. 2003a. Characterizing carbon nanotube samples with resonance Raman scattering. New J Phys 5: 139.1-139.17.

Jorio A, Pimenta Ma, Souza Filho AG, Samsonidze Ge G, Swan AK, Unlu MS, Goldberg BB, Saito R, Dresselhaus G and Dresselhaus MS. 2003b. Resonance Raman spectra of carbon nanotubes by cross-polarized light. Phys Rev Lett 90: 107403.

Jorio A, Saito R, Dresselhaus G And Dresselhaus MS. 2004. Determination of nanotubes properties by Raman spectroscopy. One contribution of 13 to a Theme Raman spectroscopy in carbons: from nanotubes to diamond. Philosophical Transactions of the Royal Society A: Mathematical, Physical and Engineering Sciences 362: 2311-2336.

Jorio a, Fantini C, Pimenta Ma, Capaz RB, Samsonidze Ge G, Dresselhaus G, Dresselhaus MS, Jiang J, Kobayashi N, Grüneis A and Saito R. 2005. Resonance Raman spectroscopy $(n, m)$ dependent effects on the resonance Raman spectroscopy for small diameter single-wall carbon nanotubes. Phys Rev B 71: 075401.

Kataura H, Kumazawa Y, Maniwa Y, Umezu I, Suzuki S, Ohtsuka Y and Achiba Y. 1999. Optical properties of single-wall carbon nanotubes. Synthetic Met 103: 2555-2558.

Kiel A, Damen TC, Porto SPS, Singh S And Varsanyi F. 1968. Asymmetry in the electronic and phonon Raman effects in CeCl3. IEEE J Quantum Elect 4: 318.

Kittel C. 2005. In: Wiley (Ed). Introduction to the Solid State Physics, $8^{\text {th }}$ ed., 559 p.

Kurti J, Magyar C, Balazs A and RajCzy P. 1995. Vibrational analysis for short carbon chains with alternating and cumulenic structure. Synthetic Met 71: 1865-1866.

LEITE RCC AND DiGiovanni AE. 1967. Frequency shift with temperature as evidence for donor-acceptor pair recombination in relatively pure $n$-type GaAs. Phys Rev 153: 841-843.

LeIte RCC AND Porto SPS. 1966. Enhancement of Raman Cross Section in CdS due to resonant absorption. Phys Rev Lett 17: 10-12.

Leite RCC, Sarace JC, Olson DH, Cohen BG, Whelan JM and Yariv A. 1965. Injection Mechanisms in GaAs Diffused Electroluminescent Junctions. Phys Rev A 137: 1583-1590.

MELo FEA. 1983. Transições de fase e efeitos anarmônicos nas vibrações da rede do $\mathrm{LiTiO}_{3+}$ estudados com espalhamento (Raman). PhD Thesis. Universidade Estadual de São Paulo, UNICAMP, Campinas, SP, Brasil.

Mendes Filho J. 1984. Espalhamento Raman e transição de fase no $\beta$-LiTiO 3 . PhD Thesis. Universidade Estadual de São Paulo, UNICAMP, Campinas, SP, Brasil.

Mendes Filho J, Lemos V, Cerdeira F, Katiyar RS, Hazen RM and Finger LW. 1984. FingerRaman and X-ray studies of a high-pressure phase transition in $\beta$ - $\mathrm{LiIO}_{3}$ and the study of anharmonic effects. Phys Rev B 30: 7212-7218.

O’Connell mu, Bachilo SM, Huffman XB, Moore VC, Strano MS, Haroz EH, Rialon KL, 
Boul PJ, Noon Wh, Kittrell C, Ma J, Hauge RH, Weisman RB and Smalley Re. 2002. Band gap fluorescence from individual single-walled carbon nanotubes. Science 297: 593-596.

Pimenta ma, marucci A, Empedocles S, Bawendi MG, Hanlon eb, Rao AM, Eklund pC, Smalley RE, Dresselhaus G and Dresselhaus MS. 1998. Raman modes of metallic carbon nanotubes. Phys Rev B 58: R16016-R16019.

Porto SPS, Tell B AND Damen TC. 1966. Near-forward Raman scattering in zinc oxide. Phys Rev Lett 16: 450-452.

RAman CV. 1930. Nobel lecture. Proc Phys Soc 42: 309-320.

RAO ADP, KATIYAR RS AND PORTO SPS. 1972. Relation between Phonon Structure and Phase Transition in $\mathrm{NaClO}_{3}$. Phys Rev Lett 28: 665-668.

RAO ADP, ANDRADE PDR AND Porto SPS. 1974. Phonon behavior and disorder mechanism in $\mathrm{NaClO}_{3}$. Phys Rev B 9: 1077-1084.

Rao AM, Richter E, Bandow S, Chase B, Eklund PC, Williams KWA, Fang S, Subbaswamy KR, Menon M, Thess A, Smalley RE, Dresselhaus G and Dresselhaus MS. 1997. Diameterselective Raman scattering from vibrational modes in carbon nanotubes. Science 275: 187-191.

RIBEIRO PHS. 1995. Estudo das propriedades de coerência da luz produzida na conversão paramétrica descendente. PhD Thesis. Universidade Federal de Minas Gerais, Belo Horizonte, MG, Brasil.

Ribeiro PHS, PÁdua S, DA Silva JCM and Barbosa GA. 1994a. Controlling the degree of visibility of Young's fringes with photon coincidence measurements. Phys Rev A 49: 4176-4179.

Ribeiro PHS, Monken CH and Barbosa GA. 1994b. Measurement of coherence area in parametric downconversion luminescence. Appl Optics 33: 352-355.

Rubim J, Gutz IGR, SAla O And ORVILle-Thomas WJ. 1983. Surface enhanced Raman-spectra of benzotriazole adsorbed on a copper electrode. J Mol Struct 100: 571-583.

Saito R, Dresselhaus G and Dresselhaus MS. 1998. Physical Properties of Carbon Nanotubes. Imperial College Press, London, UK.

Samsonidze Ge G, Saito R, Jorio A, Pimenta Ma, Souza Filho AG, Gruneis A, DresselHAUS G AND DRESSElHaUS MS. 2003. The concept of cutting lines in carbon nanotube science. J Nanosci Nanotechnol 3: 431-458.

Samsonidze Ge G, Saito R, Kobayashi N, Gruneis A, Jiang J, Jorio A, Chou SG, DresSElHAUS G AND DRESSElHaus MS. 2004. Family behavior of the optical transition energies in single-wall carbon nanotubes of smaller diameters. Appl Phys Lett 85: 5703-5705.

SCOTT JF AND PORTO SPS. 1967. Longitudinal and transverse optical lattice vibrations in quartz. Phys Rev 161: 903-910.

SCott JF, Leite RCC And DAmen TC. 1969. Resonant Raman effect in semiconductors. Phys Rev 188: $1285-1290$.

Souza FILHO AG. 2001. Propriedades eletrônicas, estruturais e vibracionais dos nanotubos de carbono e do sistema ferroelétrico $\mathrm{PbZr}_{1-x} \mathrm{O}_{3}$. PhD Thesis. Universidade Federal do Ceará, Fortaleza, CE, Brasil. 
STAMMREICH H. 1956. Technique and results of excitation of Raman spectra in the red and near infrared region (Lecture delivered at the Oxford Meeting of the European Molecular Spectroscopy Group, 1955). Spectrochim Acta 8: 41-45.

STAMmREICH H, BASSI D AND SALA O. 1958. The Raman spectrum and force constants of the chromateion. Spectrochim Acta 12: 403-405.

StammReich H, SALA O AND TAVARES Y. 1959. Raman spectra of metal carbonyl compounds I. Raman spectrum and structure of iron-pentacarbonyl. J Chem Phys 39: 856-857.

Stammreich H, Kawai K, Sala O And Krumholz P. 1961a. Raman spectra of metal carbonyl compounds. III. Raman spectrum, vibrational analysis, and bond structure of nickel tetracarbonyl. J Chem Phys 35: 2168.

Stammreich H, Kawai K, Sala O and Krumholz P. 1961b. Raman spectra of metal carbonyl compounds. IV. Raman spectra and structure of cadmium and mercury cobalt carbonyl. J Chem Phys 35: 2175.

Weber A, Porto SPS, Cheesman LE and Barrett JJ. 1967. High-resolution Raman spectroscopy of gases with cw-laser excitation. J Opt Soc Am 5: 9-28.

WiLliams PF AND PORTO SPS. 1973. Symmetry-forbidden resonant Raman scattering in $\mathrm{Cu}_{2} \mathrm{O}$. Phys Rev B 8: 1782-1785.

Worlock JM And Porto SPS. 1965. Raman scattering by $F$ centers. Phys Rev Lett 15: 697-699.

YARIV A AND LEITE RCC. 1963. Dielectric-waveguide mode of light propagation in $p-n$ junctions. Appl Phys Lett 2: 55-57.

ZhaO X, ANdo Y, LiU Y, Jinno M AND SUZUKi T. 2003. Carbon nanowire made of a long linear carbon chain inserted inside a multiwalled carbon nanotube. Phys Rev Lett 90: 187401. 